\title{
Three decades of international RILEM activities to combat deleterious Alkali-Silica Reactions (ASR) in concrete.
}

\author{
Børge Johannes Wigum ${ }^{1,2}$ *, and Jan Lindgård ${ }^{3}$ \\ ${ }^{1}$ Norwegian University of Science and Technology. Sem Sælands veg 1, N-7491 Trondheim, Norway \\ ${ }^{2}$ HeidelbergCement Northern Europe - Lilleakerveien 2B, 0283 Oslo, Norway \\ ${ }^{3}$ SINTEF Building and Infrastructure, $\mathrm{Pb} 4760$ Sluppen, 7465 Trondheim, Norway
}

\begin{abstract}
Since 1988, the International Union of Laboratories and Experts in Construction Materials, Systems and Structures (RILEM) Technical Committees (TCs) have been seeking to establish universally applicable test methods for assessing the alkali-reactivity potential of aggregates, and from later on, for concrete mixes. TC $106(1988-2001)$ focused on accelerated aggregate tests. The successor committee TC 191-ARP (2001 - 2006) also included work on diagnosis/appraisal \& specification. TC 219-ACS (2006 - 2014) introduced work on performance testing \& modelling. The major recommendations were published as a RILEM State-of-the-art Report in 2016. In 2014, TC 258-AAA was established, scheduling to finish the work on performance-based assessment in 2019. This current TC is focusing on the following Work Packages; WP1- Performance based testing concepts, WP2 - Relationship between results from laboratory and field and the establishment of field exposure sites, WP3 - Testing of potential alkalis released from certain types of aggregates and measurement of internal concrete alkali content, and eventually; WP4 - Verification of alkalis released from aggregates.
\end{abstract}

\section{Introduction}

\subsection{Alkali-Silica Reactions (ASR)}

Alkali-Silica Reactions (ASR) can be defined as chemical reactions between the alkalis hydroxides (sodium and potassium) in the pore solution of concrete and certain minerals in the aggregate. The product of the ASR is a hygroscopic gel that expands upon hydration and may introduce cracking in the surrounding concrete, thereby reducing the mechanical properties of concrete and structure service-life and increasing cost for society. The incubation time needed before ASR damage starts ranges from a few months to several decades, much depending on aggregate type, binder type, and exposure climate.

\section{Background of RILEM activities}

Development and assessments of universally test methods, in order to avoid deleterious Alkali Aggregate Reactions (AAR) in concrete, have been the focus of the RILEM Technical Committees (TC) for 3 decades. The first TC regarding AAR was established in 1988 as TC 106, with Dr Philip Nixon from the Building Research Establishment (BRE) in the UK as the Chairman, and Dr Ian Sims from Sandberg, UK (now with RSK Environment Ltd) as the secretary. The TC had been proposed by Micheline Regourd-Moranville. The formation of this TC was reported at the $8^{\text {th }}$ International Conference on Alkali Aggregate Reaction (ICAAR) in Kyoto (1989), where the $2^{\text {nd }}$ and $3^{\text {rd }}$ meetings of the TC were held immediately before and during the conference. The primary objective of the TC was to develop tests for aggregate reactivity that could form the basis for internationally agreed methods and progress, as presented by Nixon \& Sims [1].

In addition, some extra tasks were taken on, in particular a survey of national specifications for avoidance of AAR damage, and carrying out an assessment of reports of damage to structures made with low alkali cement or which contain fly ash or ground granulated blast-furnace slag. In 1993, an interim report was presented on the progress of the TC-106 in developing tests for aggregate reactivity which could form the basis for internationally agreed methods (Nixon \& Sims [2]). In 1996, TC 106 had members from 21 countries including virtually all those, which at that time, were regarded as having significant AAR problems. The TC conducted a survey of test methods in use in the participating countries, presented by Nixon \& Sims [3]. Following trials to demonstrate effectiveness in differentiating reactive and non-reactive aggregate combinations worldwide, TC-106 finalised two expansion tests in 2000 presented by Nixon and Sims [4] at the $11^{\text {th }}$ ICAAR in Québec City (2000). The concrete prism test was considered reliable for most aggregate

* Corresponding author: BorgeJohannes.Wigum@heidelbergcement.com 
combinations, and an accelerated mortar-bar test was in many cases found suitable for predicting behaviour in the concrete test.

The work of TC 106 culminated in 2000 in an integrated assessment scheme, presented by Sims \& Nixon [5]. After considering a wide range of methods for assessing aggregates for AAR, TC-106 initially concentrated on a three stages procedure:

1) Petrographical examination (AAR-1), [6]

2) Accelerated mortar-bar expansion test (AAR-2), [7]

3) Concrete-prism expansion test (AAR-3), [8]

The successor committee TC 191-ARP (AlkaliReactivity \& Prevention - assessment, specification and diagnosis), formed in 2000, continued working on an accelerated test for concrete (AAR-4) and specialised procedures for carbonate aggregates (AAR-5). This TC also had a widened scope to seek international consistency in approaches to diagnosis (AAR-6.1) and specification (AAR-7) and in assessment of alkali release from aggregates (AAR-8). The overall progress of TC 191-ARP was presented by Sims et al. [9] and Nixon et al. [10] at the $12^{\text {th }}$ ICAAR in Beijing (2004). Following discussions at the $11^{\text {th }}$ and the $12^{\text {th }}$ ICAAR conferences, TC 191-ARP developed the basis of a specification to avoid AAR damage to concrete worldwide (Sims \& Nixon [11] and Nixon \& Sims [12].

The $3^{\text {rd }}$ TC 219-ACS (Alkali aggregate reaction in Concrete Structures: performance testing and appraisal) was established in 2007, presenting findings at the ICAARs in Trondheim (2008) and in Austin (2012). The committee terminated its activities in early 2014, and concluded the work of the three TCs chaired by Dr Nixon with Dr Sims as the secretary for 25 years - see Figure 1. In recognition that damaging expansion involves interaction between all the main components of a concrete mix, TC 219-ACS also focused on the assessment of the effect of the cement/binder on ASR, i.e. performance testing. Several documents and recommendations were prepared in the TC, of which two were published during the course of the work: Lindgård et al. [13], [14] and Godart et al. [15].

The full set of RILEM Recommendations was finally published in 2016 (Nixon \& Sims [16], Figure 2). This State-of-the-art Report contains five recommended test methods for aggregates (designated AAR-1 to AAR5) and an overall recommendation which describes how these should be used to enable a comprehensive aggregate assessment (AAR-0). Additionally, in this report, there are two Recommended International Specifications for concrete (AAR-7.1 \& 7.2) and a Preliminary International Specification for dams and other hydro structures (AAR-7.3), which describe how the aggregate assessment can be combined with other measures in the design of the concrete to produce a concrete with a minimised risk of developing damage from AAR.

There has also been considerable effort in publishing a petrographic atlas by Fernandes et al. [17]. This RILEM AAR 1.2 Atlas is complementary to the petrographic method described in RILEM AAR 1.1. It is designed and intended to assist in the identification of alkali-reactive rock types in concrete aggregate by thinsection petrography.

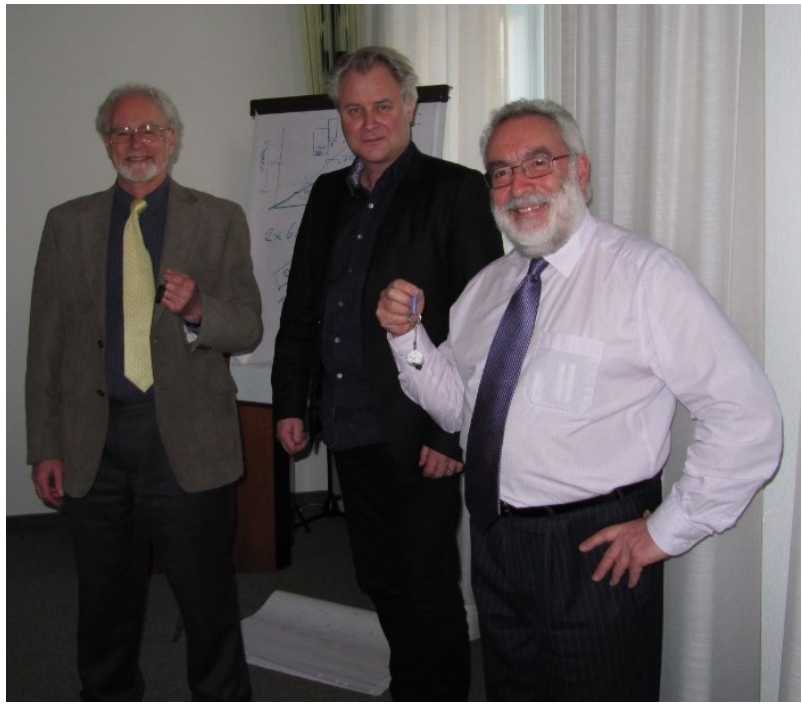

Fig. 1. Honoured after 25 years of service in RILEM Technical Committees (TCs). Heading the three TCs since 1988; Dr Philip Nixon - Chairman (left), and Dr Ian Sims - Secretary (right). Professor Børge Johannes Wigum (middle) is the Chairman of the current RILEM TC 258-AAA.

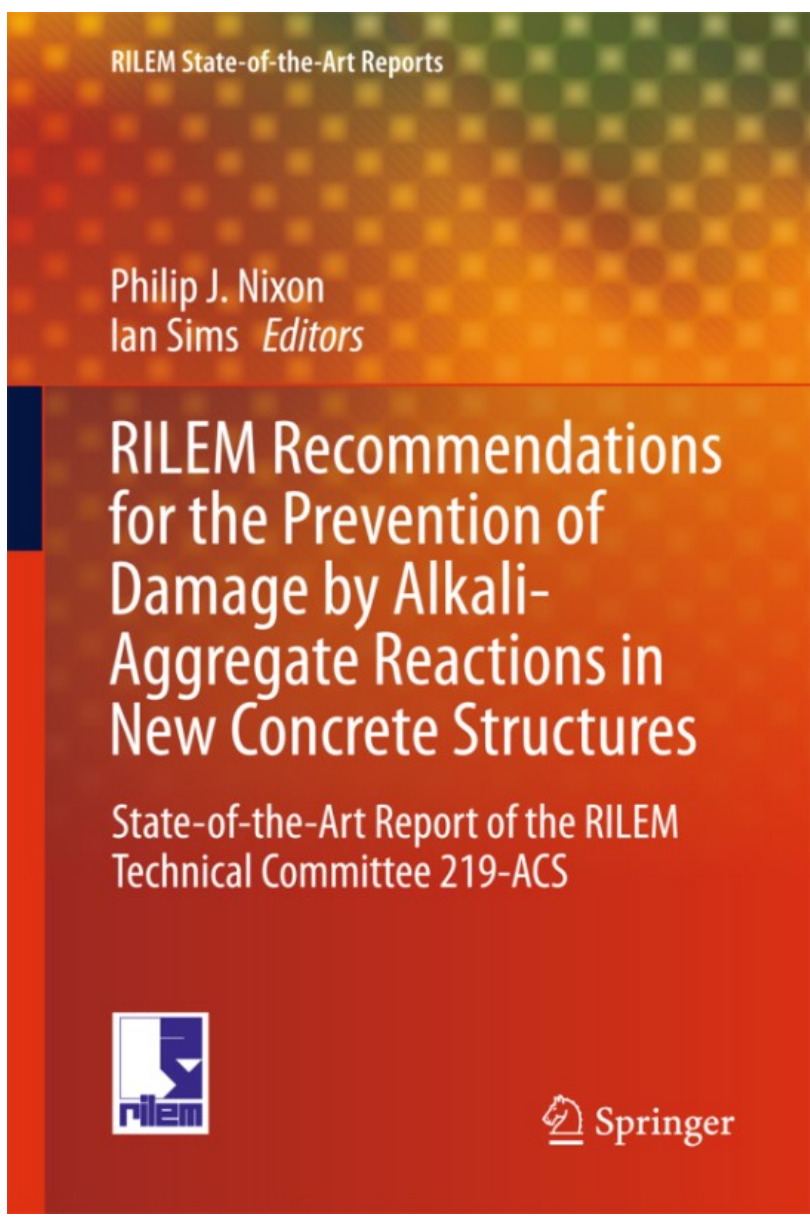

Fig. 2. Facsimile of the RILEM State-of-the-Art Report: RILEM Recommendations for the Prevention of Damage by Alkali-Aggregate Reactions in New Concrete Structures [16]. 


\section{The current RILEM TC 258-AAA}

The current, $4^{\text {th }}$ RILEM TC on AAR (TC 258-AAA) started in October 2014, and is chaired by Professor Børge Johannes Wigum (HeidelbergCement Northern Europe, Norway), and the secretary is Dr Jan Lindgård (SINTEF, Norway).

The main purpose of this new TC is to develop and promote a performance based testing concept for the prevention of deleterious ASR in concrete (the issue Alkali Carbonate Reaction, ACR, is not included in this TC). Strong emphasis will be put on the implementation of the RILEM methods and recommendations as national- and international standards.

The TC has a wide international membership which helps to promote the eventual international use of RILEM methods and recommendations. Physical meetings twice a year are still the centre of its activities and wherever possible this is co-ordinated with major relevant international conferences to facilitate attendance. Members around the world that are not able to travel to the meetings are following the discussions through the extended minutes of the meetings. All relevant documents, including the minutes from the meetings, are available for TC members at the RILEM internal website.

\subsection{The Work Packages (WPs)}

\subsubsection{WP1 - Performance testing and accelerated testing in laboratory.}

Development of performance test methods take into account the mitigating effect of supplementary materials such as fly ash or slag etc., or the specification of low alkali levels in the mix. By using such mitigation measures, a much wider selection of aggregates can be used safely while increasing the sustainability of the concrete and aggregate industry. Although such draft performance tests have been under preparation, there is still a necessity to finalize and validate these test methods, including arranging international interlaboratory trials. As soon as the necessary validation is finished, it is the intention to publish these methods as RILEM Recommendations. WP1 is headed by Dr Terje F. Rønning, (HeidelbergCement Northern Europe, Norway).

The main work is concentrating on the performance test concept using a $38^{\circ} \mathrm{C}$ Concrete Prism Test (CPT). Previous CPT procedures (e.g. RILEM AAR-3) included testing of alkali-reactivity of aggregate (AAR-3.1) and the determination of the alkali threshold of an aggregate combination (AAR-3.2). The performance test concept includes applications for performance assessment of combinations of aggregates and cement/binders at various or specific alkali contents. A Norwegian R\&D project (KPN-ASR) dealing with the same topic has provided valuable results and also enabled fruitful cooperation with leading researchers in Northern America.

The principles and test setup for the $38^{\circ} \mathrm{C}$ (RILEM AAR-10) concrete performance test has been agreed. During 2018, a Round Robin Test (RRT) will be initiated based on the agreed draft test procedure. However, the RRT will be conducted within the framework of the Norwegian KPN-ASR projects, addressing a limited number of laboratories. The test results will then be offered to the $\mathrm{TC}$ for inclusion of precision data in the test document. Publication of the RRT as such will of course acknowledge all participating parties, but it will not constitute a RILEM TC activity.

A more accelerated performance test procedure, the $60^{\circ} \mathrm{C}$ (RILEM AAR-11), is under development. Still, the principles and test setup for this possible alternative test procedure are being discussed within the TC.

A Japanese approach, based on the Japanese test procedure "TC-Draft of JCI-TC115FS-2013" (using alternative storage conditions) have been discussed at several TC meetings.

\subsubsection{WP2 - Performance testing and laboratory vs. field; Exposure site.}

An important additional tool in validation of the performance testing concept is to make an assessment of the link between the accelerated results from the laboratory and behaviour of these concrete mixtures in real field structures. One main objective is to establish a link between outdoor exposure sites dedicated to AAR investigations and located in different parts of the world, in order to generate an international database on the effect of environmental conditions on the kinetics of AAR. WP2 is headed by Professor Benoît Fournier (Université Laval, Québec, Canada).

The initial work has included casting of about 80 concrete cubes $(300 \times 300 \times 300 \mathrm{~mm})$ for outdoor storage and monitoring at 10 different exposure sites in Europe and North America (Portugal, France, Norway, Iceland, Germany, Canada \& the USA). The concrete mixtures included ordinary Portland cement and addition of fly ash (20\&30\%), along with control mixtures.

The EU PARTNER Project, initiated in the early 2000 s, produced concrete cubes $(300 \times 300 \times 300 \mathrm{~mm})$ from 13 aggregate combinations and distributed to eight exposure sites across Europe. In 2017, the laboratory of LNEC in Portugal shipped about 80 cores drilled from 20 PARTNER cubes after 12 years of field exposure to laboratories taking part in the post-documentation program.

An extensive State-of-the-art report on the lab./field correlation is currently being prepared.

A paper giving an overview of field exposure sites world-wide is presented by Fournier et al. [18]. 
3.1.3 WP3 - Performance testing; Assessment of detailed alkali inventory in concrete, including internal alkali release from aggregates, recycling of alkali and external alkali supply.

One important "missing link" is how to measure the amount of potential alkalis that might be released from various types of aggregates in the laboratory, under accelerated conditions. It is the intention to finalise and validate a test method for alkalis released by aggregates. As soon as the necessary validation is finished, it is the intention to publish this method as a RILEM Recommendation. It is also of important to evaluate the potential internal alkali recycling in the concrete which in some instances have been reported, in addition to assess any alkali contribution from external sources. WP3 is headed by Dr Esperanza Menéndez Méndez (Institute of Construction Science, "Eduardo Torroja" (CSIC), Spain).

A Round-Robin test has been completed in the WP3 in order to evaluate the test procedure for measuring potential amount of releasable alkalis from aggregates. In addition, initial work in WP3 includes the preparation of an outline literature review regarding the alkali inventory in concrete.

\subsubsection{WP4 - Verification of alkalis released from aggregates.}

Results of alkali release from accelerated laboratory tests need to be verified and calibrated to what happens in real structures. The aim is to compile results from exposure sites and concrete structures worldwide in order to assess the "true" level of alkali released from various aggregates. WP4 is headed by dr Klaartje De Weerdt (Norwegian University of Science and Technology, Norway).

Post-doc activities in the Norwegian KPN-ASR project have developed an efficient and assumed accurate test method to determine the alkali level in concrete facilitating activities to verify the level of potential alkali release from aggregates in real concrete.

The activities of this WP are still under planning.

\section{Concluding remarks}

We have struggled to understand, control and prevent damage from AAR in the past 75 years since it was first reported in concrete. In addition to the ICAARs, which started in 1974, the continuing series of RILEM Technical Committees has helped to harness international cooperation in this struggle for the last 30 years. The RILEM work has recently archived some significant milestones regarding recommendations to prevent damage by AAR in new concrete structures.

The work in the current TC 258-AAA will continue until 2019, with particular focus on the performance based testing concept. It is our anticipation to increase the input from all parties all around the world, enabling the implementation of the RILEM methods and recommendations as national- and internationals standards

\section{References}

1. Nixon, P.J. \& Sims, I., (1992) RILEM TC106 Alkali Aggregate Reaction - Accelerated tests. Interim Report and Summary of Survey of National Specifications. In Proceedings of the 9th International Conference on Alkali-Aggregate Reactions in Concrete (ICAAR), London, 731- 738.

2. Nixon, P.J. \& Sims, I., (1993) RILEM TC106 Alkali Aggregate Reaction - accelerated tests. Interim report. BRE Client Report CR 130/93.

3. Nixon, P. \& Sims, I., (1996) Testing aggregates for alkali-reactivity. Report of TC-106. Materials and Structures. Vol. 29, July, 323-334.

4. Nixon, P. \& Sims, I., (2000) Universally accepted testing procedures for AAR. The progress of RILEM Technical Committee 106. In Proceedings of the 11th International Conference on Alkali Aggregate Reaction (ICAAR), Québec. 435 - 444.

5. Sims, I. \& Nixon, P., (2001) Alkali-reactivity - a new international scheme for assessing aggregates. Concrete. January, 36 - 39.

6. RILEM (2003) AAR-1 - Detection of potential alkali-reactivity of aggregates - Petrographic method, Materials and Structures (36) 480-496.

7. RILEM (2000) AAR-2 - Detection of potential alkali-reactivity of aggregates - the ultraaccelerated mortar bar test, Materials and Structures (33) 283-289.

8. RILEM (2000) AAR-3 - Detection of potential alkali-reactivity of aggregates - method for aggregate combinations using concrete prisms, Materials and Structures (33) 290-293.

9. Sims, I., Nixon, P.J. \& Marion, A-M., (2004) International collaboration to control AlkaliAggregate Reaction: The successful progress of RILEM TC 106 and TC 191-ARP. In Proceedings of the 12th International Conference on AlkaliAggregate Reaction in Concrete (ICAAR), Beijing. 41- 50 .

10. Nixon, P., Hawthorn, F. \& Sims, I., (2004) Developing an international specification to combat AAR. Proposals of RILEM TC 191-ARP. In Proceedings of the 12th International Conference on Alkali-Aggregate Reaction in Concrete (ICAAR), Beijing. 8- 16.

11. Sims, I. \& Nixon, P.J., (2006) Assessment of Aggregates for Alkali-Aggregate Reactivity Potential: RILEM International Recommendations. In Proceedings of the Marc-André Bérubé Symposium on Alkali-Aggregate Reactivity in Concrete. Montreal. 71 - 91 .

12. Nixon, P. \& Sims, I., (2006) An International Specification to Combat AAR. Proposals of RILEM TC 191-ARP. In Proceedings of the Marc- 
André Bérubé Symposium on Alkali-Aggregate Reactivity in Concrete. Montreal. 195- 215.

13. Lindgård, J., Nixon, P.J., Borchers, I., Schouenborg, B., Wigum, B.J., Haugen, M. \& Akesson, U., (2010) The EU Partner project European standard tests to prevent alkali reactions in aggregates, Cement \& Concrete Research, 40, 611-635.

14. Lindgård, J., Andiç-Çakır, Ö., Borchers, I., Broekmans, M.T.A.M., Brouard, E., Fernandes, I., Giebson, C., Pedersen, B. Pierre, C., Rønning, T.F., Thomas, M.D.A. \& Wigum, B.J., (2011) RILEM TC219-ACS-P: Literature survey on performance testing, COIN project report 27, ISBN: 978-82536-1209-6, 164.

15. Godart, B. de Rooij, M. \& Wood, J.G.M. (Eds.), (2013) Guide to Diagnosis and Appraisal of AAR Damage to Concrete in Structures. Part 1 Diagnosis (AAR 6.1). Springer Series: RILEM State-of-theArt Reports, Vol. 12.91 pp.
16. Nixon, P.J. and Sims, I. (eds.), (2016) RILEM Recommendations for the Prevention of Damage by Alkali-Aggregate Reactions in New Concrete Structures, Springer Series: RILEM State-of-theArt Reports, Vol. 17, 168 pp. 1st ed. 2016, XVI, $168 \mathrm{p}$.

17. Fernandes, I., Anjos Ribeiro, M., Broekmans, M.A.T.M. \& Sims, I., (2016) Petrographic Atlas: Characterisation of Aggregates Regarding Potential Reactivity to Alkalis. RILEM TC 219-ACS Recommended Guidance AAR-1.2, for use with the RILEM AAR-1.1 Petrographic Examination Method. Springer, 1st ed. 2016, XI, 191 pp.

18. Fournier, B, Lindgård, J. \& Wigum, B.J., (2018) : Outdoor exposure site testing for preventing AlkaliAggregate Reactivity in concrete - a review. To be presented at ICCRRR 2018. 